\title{
Effect of Vertical Length on Corrosion of Steel in the Tidal Zone
}

\author{
R. Jeffrey ${ }^{\star}$ and R.E. Melchers ${ }^{\ddagger} *$
}

\section{ABSTRACT}

The corrosion loss of mild steel in the marine tidal zone varies considerably with elevation relative to mean tide. Classical studies on steel piles and electrically isolated coupons show quite different vertical corrosion profiles. This usually is attributed to the effect of differential aeration. In many practical applications, steel structures may be confined to just part of the tidal zone or may extend only partly into either the atmospheric zone or the immersion zone. This paper presents mass-loss profiles for steel strips of different lengths $(0.20$, $0.50,1.0$, and $3 \mathrm{~m}$ ) exposed at various elevations in the atmospheric, tidal, and immersion zones at Jervis Bay, Australia, where the tidal range is around $1.2 \mathrm{~m}$. Relatively little difference in the corrosion profile was observed in the corrosion profiles for 100-mm-long coupons and for the shorter strips, mainly because each strip or coupon was confined to exposure only in a single zone. However, very high, localized corrosion was observed for a 1-m strip with the lower end extending just into the immersion zone. The 3-m-long strip and the individual coupons, all extending from the immersion zone to the atmospheric zone, displayed corrosion loss profiles generally consistent with those reported in classical studies.

KEY WORDS: differential aeration, length effect, mass loss, mild steel, profile, tidal zone

\section{INTRODUCTION}

Classical studies of steel sheet piling and for closely spaced individual, electrically isolated coupons show

Submitted for publication March 2009; in revised form, June 2009.

‡ Corresponding author. E-mail: rob.melchers@newcastle.edu.au

* Centre for Infrastructure Performance and Reliability, The University of Newcastle, Australia. severe corrosion loss in the tidal zone, although the corrosion profiles are very different..$^{1-3}$ In full-scale experimental field trials (151-day and 5-year exposures) at the same site on the U.S. Atlantic seaboard (Kure Beach), individual coupons showed that the greatest losses were around the mean tide level. In contrast, continuous steel sheet piling typically showed the most severe corrosion losses around the high tide and splash zone levels. Generally, similar profiles were observed for individual coupons electrically connected together. These mass-loss profiles have been widely quoted in the literature. Earlier laboratory studies for non-tidal corrosion at around the waterline $\mathrm{e}^{4-5}$ showed that localized differences may be attributed to differential aeration, in which regions shielded from oxidation show higher corrosion loss than adjacent regions. Differential aeration has been offered as the explanation also for the corrosion profiles observed for sheet piling in the tidal zone. ${ }^{3}$

For sheet piling in tidal marine exposures, a complicating factor is that very high corrosion losses have been observed in some cases at and immediately below the low water level. This phenomenon has been termed "accelerated low water corrosion" (ALWC). A number of studies have indicated the potential involvement of bacteria, ${ }^{6}$ but the precise mechanisms and conditions under which that occurs remain to be elucidated. No clear correlation has been established so far between bacterial activity on sheet piling, water quality, and the incidence of ALWC. ${ }^{7}$ However, other studies for steel exposed to nutrient pollution situations suggest that a relationship between corrosion loss and bacterial activity as measured by nutri- 
TABLE 1

Water Quality and Other Parameters at the Jervis Bay Exposure Site

\begin{tabular}{|c|c|c|}
\hline Parameter & Units & Typical Value \\
\hline Ammonia & ppm & 0.009 to 0.045 \\
\hline Nitrate & $\mathrm{ppm}$ & $<0.005$ to 0.022 \\
\hline Nitrite & $\mathrm{ppm}$ & $<0.003$ to 0.036 \\
\hline Sulfate & ppm & 2,300 to 2,800 \\
\hline Total P & $\mathrm{ppm}$ & 0.007 to 0.008 \\
\hline $\mathrm{Ca}$ & ppm & 374 to 392 \\
\hline $\mathrm{Cl}$ & $\mathrm{ppm}$ & 21,000 \\
\hline Alkalinity & $\mathrm{ppm} \mathrm{CaCO}_{3}$ & 130 \\
\hline Salinity & ppt & 29.0 \\
\hline $\mathrm{pH}$ & & 8.2 \\
\hline $\begin{array}{l}\text { Annual mean water } \\
\text { temperature }\end{array}$ & ${ }^{\circ} \mathrm{C}$ & 19 \\
\hline
\end{tabular}

ent availability could exist, although it is not a simple one. ${ }^{8}$ In this context, it is possible that bacterial activity may be partly responsible for the corrosion profiles reported by Takamara, et al., ${ }^{9}$ for individual coupons exposed on an offshore ore-wharf dolphin in Osaka Bay, Japan, since bays typically have elevated nutrient levels. ${ }^{10}$ It is also possible that the tidal corrosion profiles reported by $\mathrm{Li}$, et al., ${ }^{11}$ were influenced by bacterial activity. Their results, for individual and for electrically connected coupons exposed in the tidal zone in the Chengdao Offshore Oil Exploration Area, were taken from an offshore oil platform. These invariably are subject to nutrient pollution. ${ }^{10}$ In the study described below, all exposures were performed at the one site. If bacterial activity was involved, it might be expected that it would have had a generally similar effect in all cases.

In practical applications, steel structures need not extend very far vertically and may be confined to just part of the tidal zone. They may not extend into either the atmospheric zone or the immersion zone. Despite the known severity of corrosion loss in the tidal zone, ${ }^{12-13}$ these scenarios appear not to have been addressed in the corrosion literature. The available information is limited to small, isolated coupons, electrically connected coupons, and to continuous sheet piling. The present paper presents new massloss results for strips of different lengths exposed at various elevations, covering one or more of immersion, tidal, splash, and atmospheric exposure zones.

\section{EXPERIMENTAL PROCEDURES}

The study was conducted at the Jervis Bay base of the Royal Australian Navy on the East Coast of Australia. It offers a relatively sheltered location with minor wave action and some splash zone activity in temperate Pacific Ocean tidal waters. It is also a secure site.

Strips of mild steel $50 \mathrm{~mm}$ by $3 \mathrm{~mm}$ in cross section and of various lengths $(0.20,0.50,1.0$, and
$3 \mathrm{~m}$ ) as well as electrically isolated coupons (100 by 50 by $3 \mathrm{~mm}$ thick) were attached with nylon bolts and washers to non-metallic support strips that, in turn, were attached to a wooden jetty. All were exposed for one year. The support strips were placed about $300 \mathrm{~mm}$ apart so as not to interfere with each other. This is sufficiently close for possible differences in atmospheric conditions, in water quality, in salinity, in $\mathrm{pH}$, and in water velocity to be considered negligible compared with the corrosion loss profiles of the strips and coupons. Table 1 summarizes the typical water quality and other parameters at the exposure site.

All strips were exposed in the "as-rolled" condition, i.e., without removal of mill scale. This was necessitated by the practical difficulty of cleaning and preparing long strips to customary corrosion testing standards. Previous studies have shown that this is likely to have only a relatively short-term effect, mainly on pitting rather than mass loss, and that after several months' exposure there is only a marginal difference between steel, acid-cleaned steel, and steel with mill scale. ${ }^{5,14-15}$

All of the strips (and coupons) were exposed for 12 months. On recovery, they were cleaned of the prolific marine growth below the water line and of loose rust and taken back to the laboratory. The strips then were guillotined immediately, precisely to individual segments of $100 \mathrm{~mm}$ length and number-punched sequentially as they were cut. Each segment was then cleaned to remove rusts according to ASTM G3 ${ }^{16}$ and the mass of each segment ascertained. The mass loss over the exposure period was calculated. For this, the original mass of each section was estimated from the density of the steel and the original dimensions (allowing where necessary for the fixing hole). Overall, the estimated uncertainty in mass loss is estimated to be $\pm 1 \%$, governed mainly by accuracy in cutting the strips to segment lengths. Table 2 gives the corrosion loss for each exposed surface of each segment, expressed in microns as a function of elevation (in meters). Figure 1 shows these results plotted at the mid-height of each segment. Best-fit trend lines are shown constructed through each data set.

\section{OBSERVATIONS}

The corrosion profile for the 3-m continuous strip is considerably different from the profiles for the shorter strips (Figure 1). It shows high localized corrosion above the mean tide level, which is in the splash zone region. This is consistent with the classical profiles of Humble, LaQue, and Larrabee. ${ }^{1-3}$ However, unlike the classical profiles, there also is considerable corrosion loss in the region immediately below the mean low tide level.

The profiles for the shorter strips (i.e., those 0.2, 0.5 , and $1 \mathrm{~m}$ long) all show high levels of corrosion loss around the mean tide level, extending into the 
TABLE 2

Corrosion Loss (in microns) After 12 Months' Exposure

as a Function of Elevation (in meters)

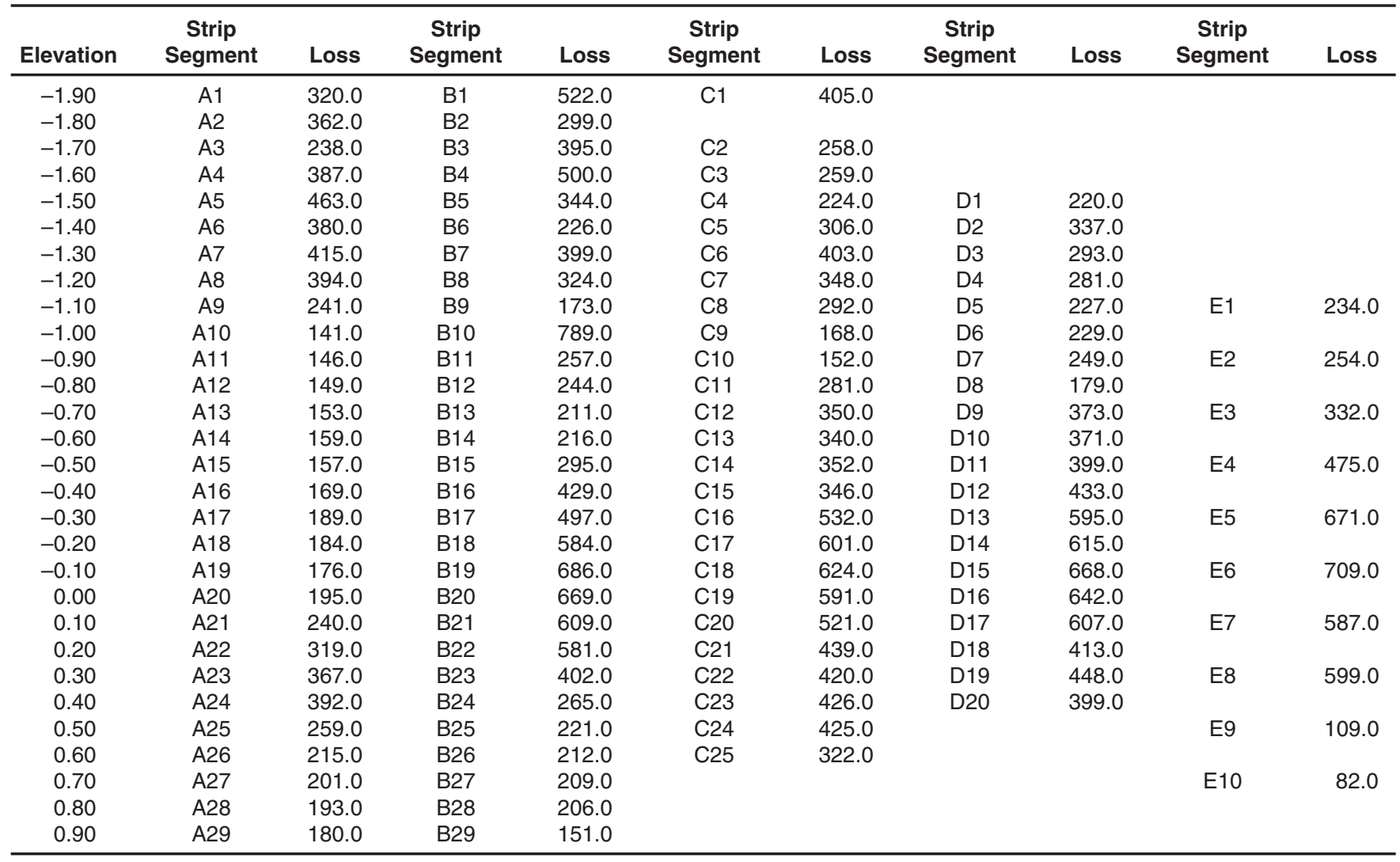

splash zone and the upper immersion zone (Figure 1). They are similar to the corrosion loss profile for the coupons, which, in turn, is consistent with the profiles reported in the various classical studies. All these profiles also show high corrosion losses in the region well below the mean low water level (say below $-1.0 \mathrm{~m}$ ), a phenomenon not observed in the classical studies. This is not an isolated incident, with the corrosion profiles being remarkably consistent between the various shorter strips and generally similar to the profile for the coupons, despite some variability, as evident in Figure 1.

The corrosion profiles (Figure 1) can be compared directly with photographs of the surfaces of the corroded segments for each of the different strips (Figure 2 ). This shows that there is considerable variation in the character of the corroded surfaces both between the strips at any one elevation and for different elevations. Evidently, the low loss regions in Figure 1 correspond with relatively smooth corroded surfaces in Figure 2. These may be associated with cathodic zones. ${ }^{5}$ In contrast, the high loss regions in Figure 1 correspond with the more severe corrosion evident in Figure 2 and these are likely to be anodic regions. ${ }^{17}$ In the immersion zone the anodic region has discrete pitting on relatively smooth surfaces (Figures 2[c]

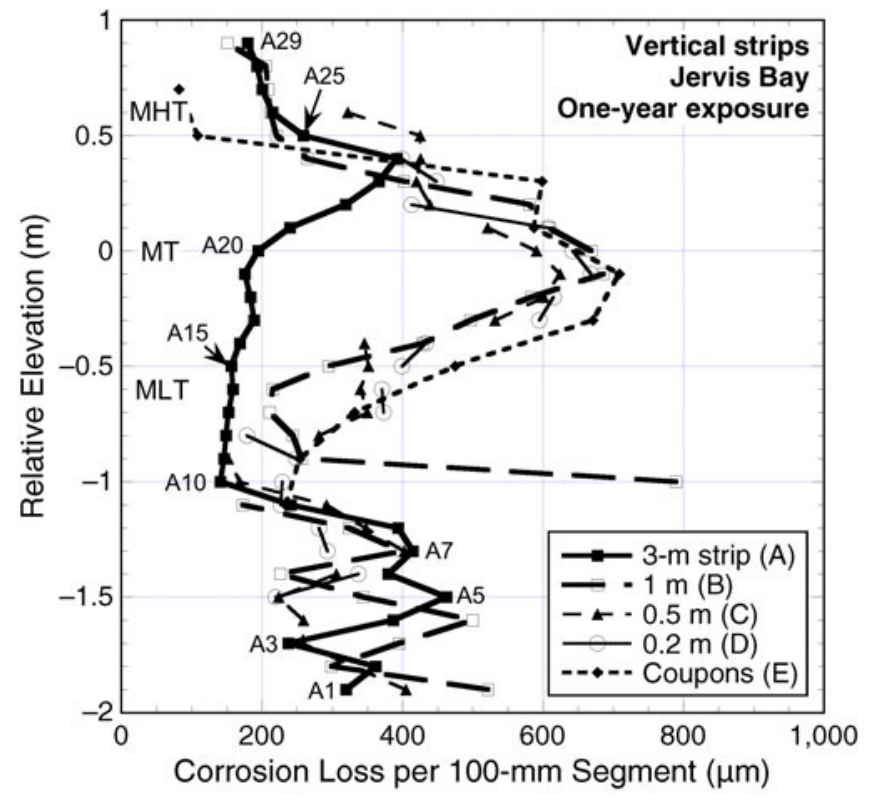

FIGURE 1. Corrosion loss (in microns) after 12 months' exposure, plotted at the mid-height of each 100-mm segment of strip (or at coupon mid-height). The mean high tide (MHT), mid tide (MT), and mean low tide $(M L T)$ levels are indicated. 


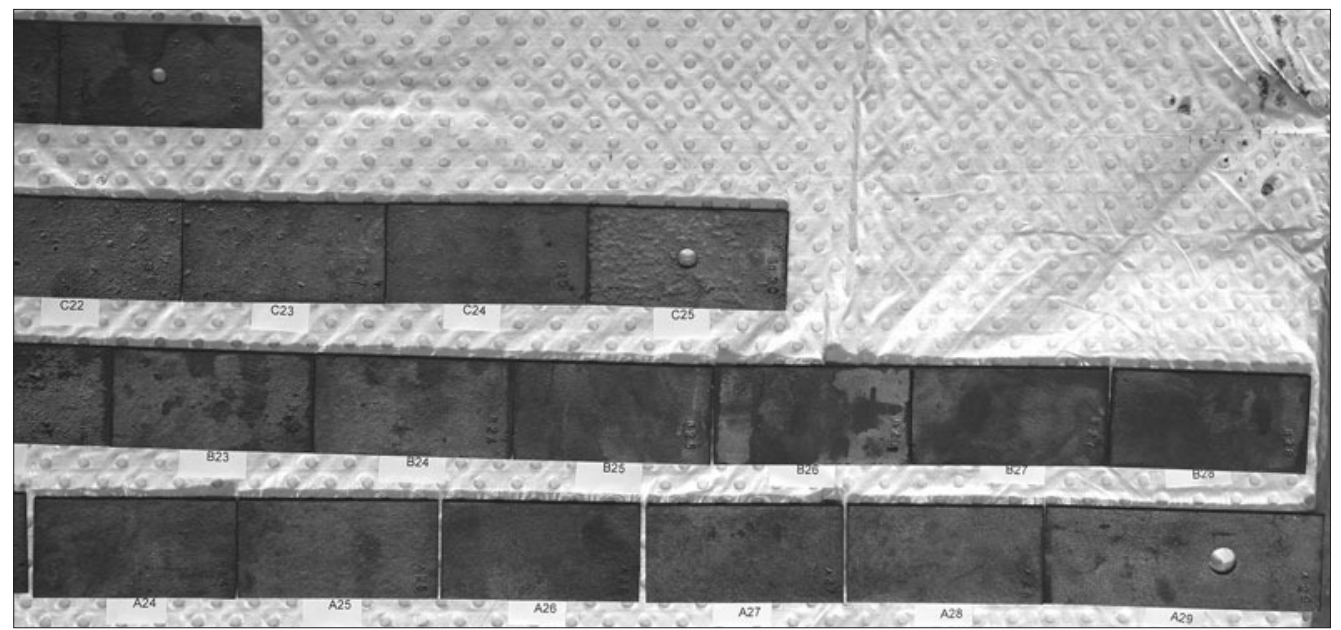

(a)

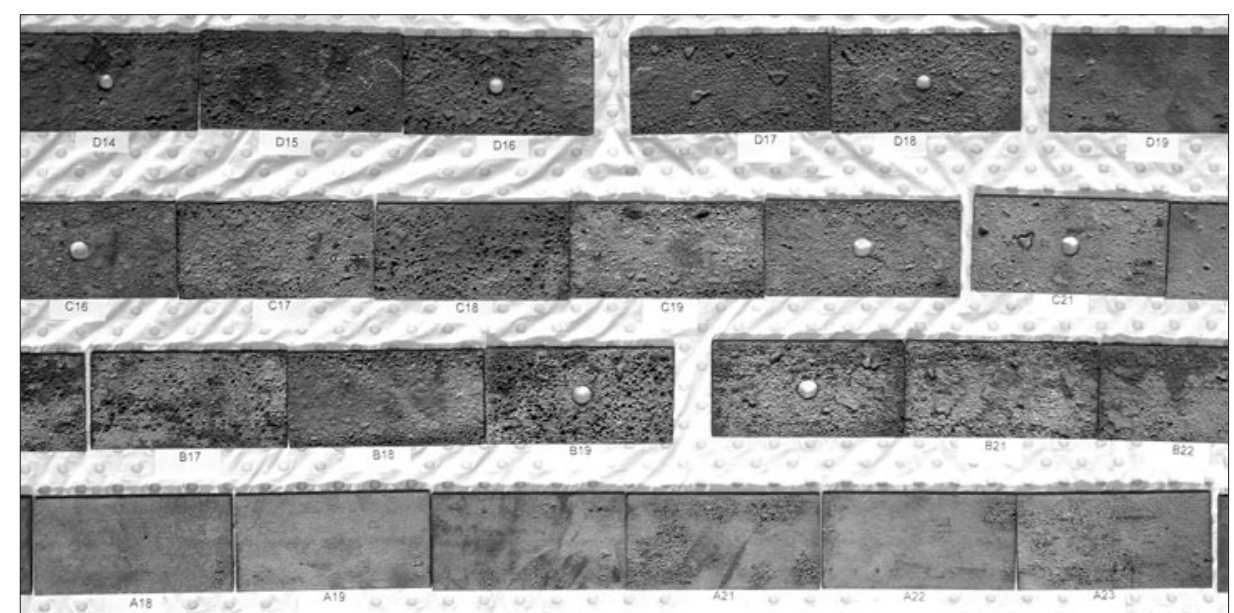

(b)

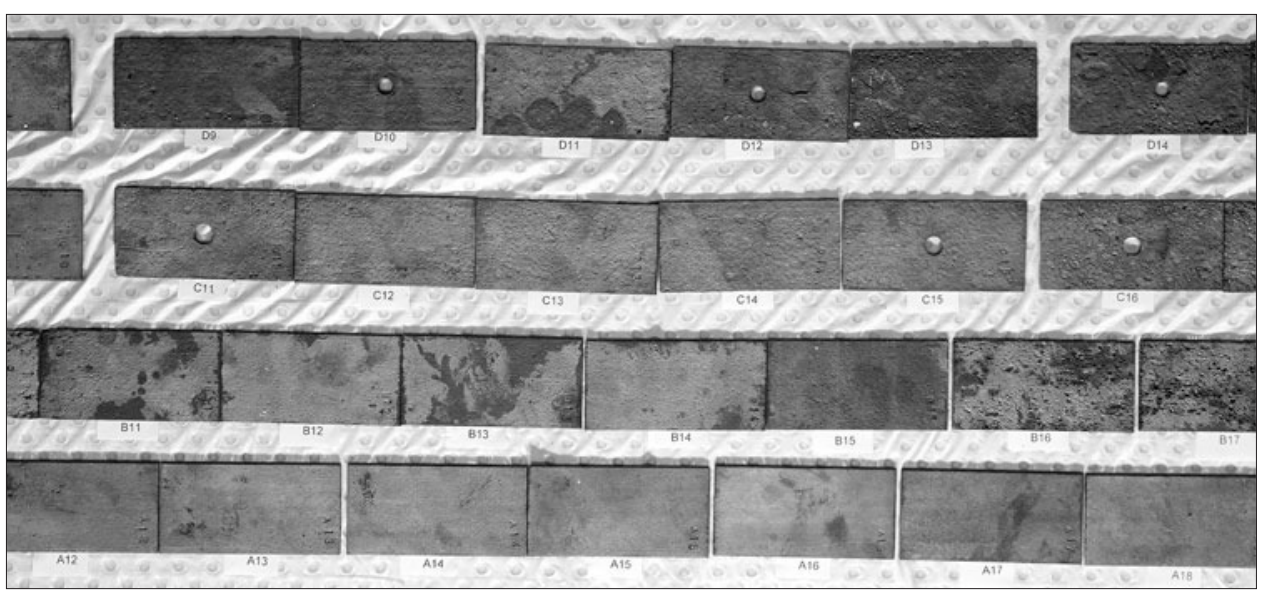

(c)

FIGURE 2 (continued on next page). (a) Segments A24 through A29 and corresponding others (atmospheric zone: $0.4 \mathrm{~m}$ to $0.9 \mathrm{~m}$ ). (b) Segments A18 though A23 and corresponding others (mean tide and splash zone: $0.2 \mathrm{~m}$ to $0.8 \mathrm{~m}$ ). (c) Segments $A 12$ through $A 17$ and corresponding others (upper immersion zone: $0.8 \mathrm{~m}$ to $0.3 \mathrm{~m}$ ). (d) Segments $A 8$ through $A 11$ and corresponding others (upper immersion zone: $1.2 \mathrm{~m}$ to $0.9 \mathrm{~m}$ ). (e) Segments $A 1$ through $A 7$ and corresponding others (immersion zone: $1.9 \mathrm{~m}$ to $0.8 \mathrm{~m}$ ). Segments of various strips arranged from (a) atmospheric through (e) immersion within each case-the segments arranged, from top, 0.2-m strips $D$, 0.5- $\mathrm{m}$ strips $C$, 1.0-m strips $B$, and the 3-m strip $A$ at bottom. The labeling of segments is from the lower immersed edge upward (see also Figure 1). 


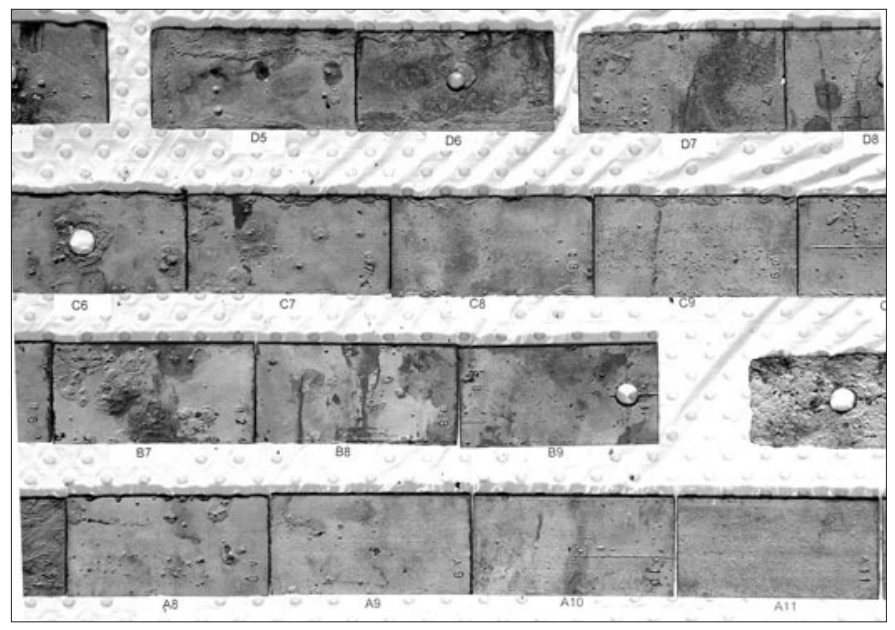

(d)

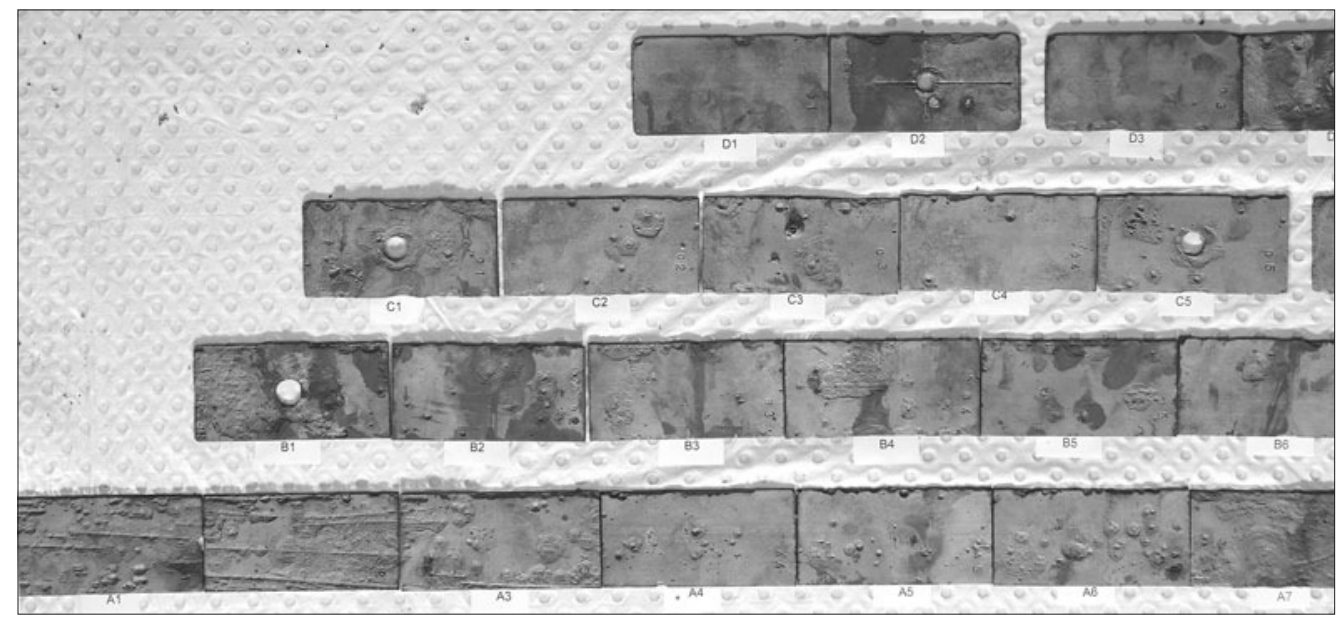

(e)

FIGURE 2 (continued). (a) Segments A24 through A29 and corresponding others (atmospheric zone: $0.4 \mathrm{~m} \mathrm{to} 0.9 \mathrm{~m}$ ). (b) Segments A18 though A23 and corresponding others (mean tide and splash zone: $0.2 \mathrm{~m}$ to $0.8 \mathrm{~m}$ ). (c) Segments A12 through $A 17$ and corresponding others (upper immersion zone: $0.8 \mathrm{~m}$ to $0.3 \mathrm{~m}$ ). (d) Segments A8 through $A 11$ and corresponding others (upper immersion zone: $1.2 \mathrm{~m}$ to $0.9 \mathrm{~m}$ ). (e) Segments A1 through $A 7$ and corresponding others (immersion zone: $1.9 \mathrm{~m}$ to $0.8 \mathrm{~m}$ ). Segments of various strips arranged from (a) atmospheric through (e) immersion within each case-the segments arranged, from top, 0.2-m strips $D$, 0.5-m strips C, 1.0-m strips $B$, and the 3- $m$ strip $A$ at bottom. The labeling of segments is from the lower immersed edge upward (see also Figure 1).

through [e]) but in the splash zone it corresponds to very aggressive pitting (Figure $2[\mathrm{~b}]$ ). This pattern is common for the coupons and for all strips other than the 3-m strip. It corresponds with the respective corrosion loss profiles.

Several other observations can be made. Figure 2 shows a very high corrosion loss for segment $\mathrm{B} 10$, that is, at the lower end of the middle 1-m-long strip. The corresponding image of this segment shows severe corrosion (Figure 2[d]). Figure 3(a) shows this segment together with the start of the strip immediately below it (to the left) to indicate the severity of the localized corrosion. Evidently, this segment of the 1-m strip is located just below the mean low tide level, indicating that it is immersed for most of the year (except for a relatively short period during king tides).
Thus, it is likely to develop more corrosion product and, being continuously immersed, be exposed to lower oxygen availability than the rest of the strip above it. It is highly likely that differential aeration will occur with the result that this segment will be anodic relative to the rest of the strip above it. Consequently, it will corrode at a high rate. A generally similar high degree of localized corrosion was observed at the end of segment B1 at the very bottom end of the B strips (Figure 3[b]). This also could be the result of differential aeration. The shorter strips D $(0.2 \mathrm{~m})$ do not show evidence of greater corrosion at the ends of the strips. This is likely to be related to each of these strips being exposed essentially to only one exposure zone. This is also the case for most of the strips C (0.5 m). 


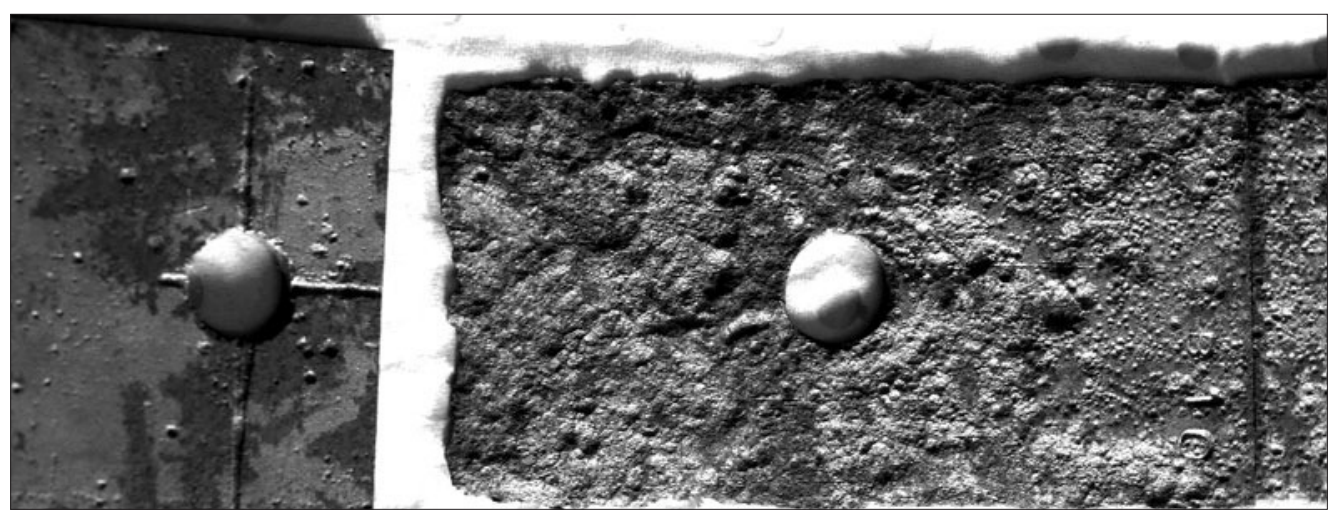

(a)

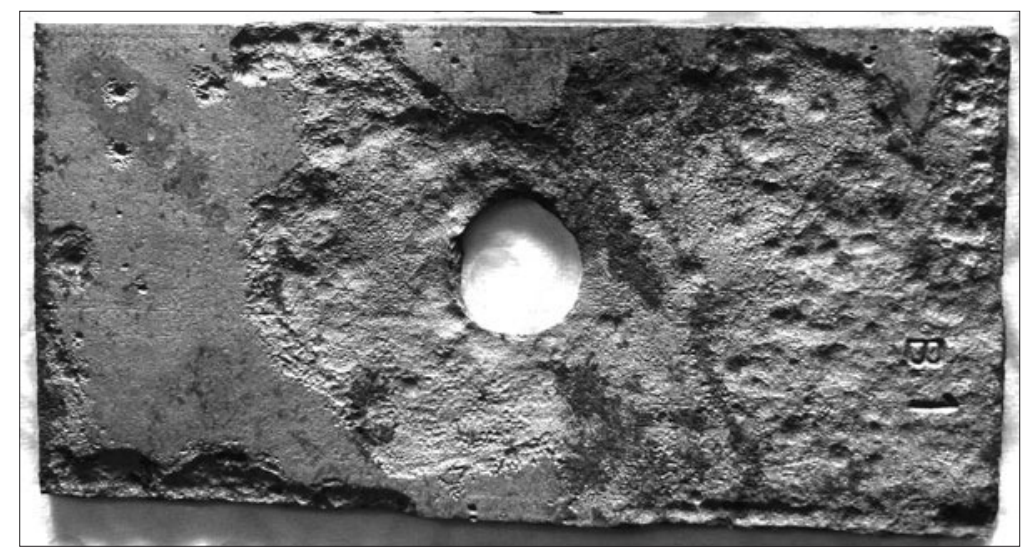

(b)

FIGURE 3. (a) Segment B10 (right) showing severe corrosion relative to (part of) segment B11 (left), which is at the top of the next strip below. (b) Segment B1 showing the high degree of corrosion at the end of the lowest B strip (i.e., continuously fully immersed).

The corroded surfaces of the steel in the upper tidal zone (Figure 2 at A17 through A23 and corresponding others) is rather rough in appearance for the shorter strips, with clear evidence of widespread pitting and several much deeper, larger pits. Superficially, this suggests anodic conditions. For the long strip A, the surfaces of the segments are much smoother. At lower depths, all segments show relatively smooth corroded surfaces, corresponding to lower corrosion losses (Figure 1).

In general, a balance between anodic and cathodic regions appears to exist along the length of the longer strips (A, B), as expected from fundamental considerations. However, this was not seen for the individual coupons (E), irrespective of precise exposure zones. For these, it is difficult to discern evidence of cathodic regions, and typically the coupons tend to have more or less the same degree of roughness all over. To be sure, there are differences between the coupons from different exposure zones, corresponding roughly to the degree of mass loss. Since cathodic regions must be present to allow corrosion to proceed, it is possible that some of the rough surfaces are, or were at one time, actually cathodic regions. ${ }^{18}$ Gener- ally, similar observations hold for the 0.2-m strips (D, Figure 4). Compared to the longer strips, these also show evidence of rough surface textures and a lack of smooth cathodic surfaces. However, there is also clearly defined pitting and this can be interpreted as anodic regions surrounded by (rather rough-textured) cathodic regions, presumably once part of much more localized and much smaller pitting.

There is evidence of corrosion around some of the holding bolt holes (Figure 3 at left) and at scribe marks for locating the hole prior to drilling, presumably the result of crevice corrosion. It is likely that some of the other deeper corrosion lines on the metal surface (Figure 2) are the outcome of corrosion of what were originally fine scratches possibly caused during the machining and handling of the steel strips but not seen, at the time of exposure, as critical.

\section{DISCUSSION}

As noted, the corrosion profiles for the continuous strip, the shorter strips, and the individual coupons are generally consistent with the classical profiles, at least above about the mean low tide 


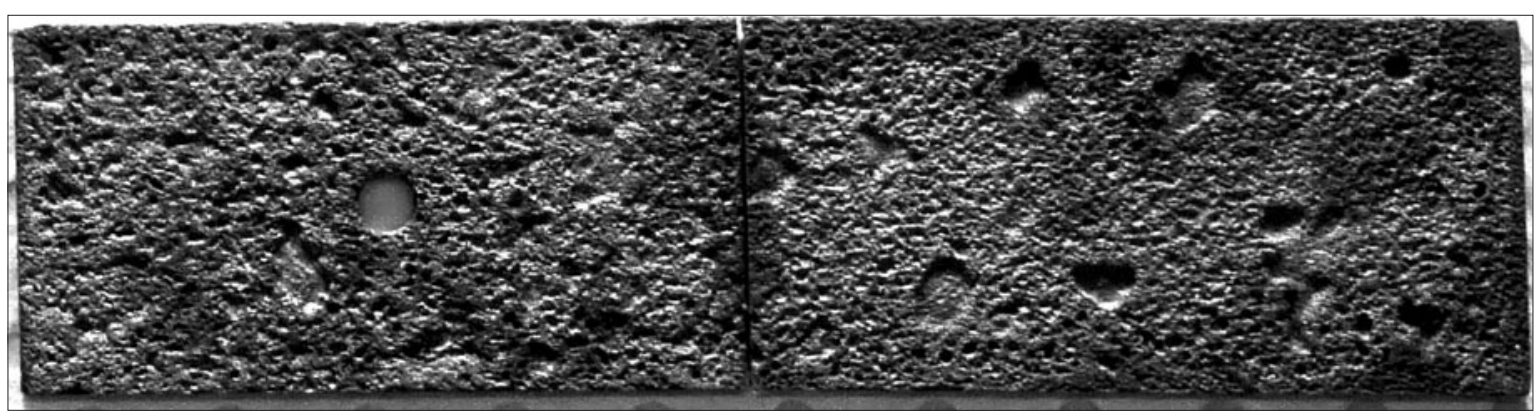

FIGURE 4. A type D (0.2 m long) strip consisting of two segments showing a generally rough surface with localized severe pitting. The hole at left is for the holding bolt.

(MLT) level. However, the present results all show a higher degree of corrosion at lower levels. The higher degree of local corrosion in the (almost) continuously immersed zone, while not a classical result, is not unusual and can be seen, for example, in the data reported for isolated and for electrically connected coupons exposed in the Changdao Offshore Oil exploration region off the Chinese coast. ${ }^{11}$ For individual coupons, that effect previously has been attributed to the influence of bacterial activity, consistent with oil fields being a known source of elevated nutrient levels and with other data supporting the proposition. ${ }^{19}$ Despite considerable variability between corrosion losses at different elevation levels, Figure 1 shows that overall the corrosion for the strips below about MLT is considerably greater than for the very short strips (D) and coupons (E). This suggests that while there may be a direct bacterial effect similar to that for individual small coupons, there also is likely to be a differential aeration effect from the enhanced corrosion and hence corrosion product caused by bacterial activity. Although likely, there is no direct evidence for these propositions. They remain for further investigation.

The oscillatory nature of the corrosion losses below MLT (Figure 1) also is of interest. This phenomenon appears not previously to have been reported in the literature. It is present in all the strip corrosion profiles and to a (much) lesser extent for the coupons. This indicates that it is not some error caused by experimental procedure or data analysis. The oscillatory period is about $200 \mathrm{~mm}$ to $300 \mathrm{~mm}$ and this may be why this phenomenon was not observed in the classical studies, since these used $300-\mathrm{mm}$ coupons and 300-mm-length segments for strip analyses. Figure 2 shows that below the MLT the metal surfaces show the relatively smooth corrosion surfaces with characteristic random shallow pitting normally associated with shorter-term immersion corrosion..$^{20}$ The effect is more pronounced for shorter strips, consistent with the observation that the coupons generally have a rougher surface texture. As noted, for the strips, this behavior is likely to be influenced by differential aeration and the associated alternation of anodic and cathodic regions, the effect dissipating with depth as observed for non-tidal exposure at the same site. ${ }^{17}$

The potential influence of bacterial activity on corrosion below MLT can be expected to have some influence on corrosion at higher elevations, although it cannot be ascertained from the profiles reported herein. It also raises the question of the degree to which nutrient availability influences the corrosion profile, particularly below MLT. Such an influence would be expected, based on the recently demonstrated influence of nutrient availability for the marine immersion corrosion of steel coupons. ${ }^{19}$ It also is a matter of interest for accelerated low water corrosion (ALWC) of sheet piling, for which bacterial activity has been implicated.$^{6-7}$ However, a definitive correlation between bacterial activity, nutrient availability, and accelerated corrosion has not yet been demonstrated. Field studies currently in progress at various sites on the East Coast of Australia are expected to shed some light on this issue.

Finally, it is noted that the present results reinforce the observations for corrosion in the tidal zone that it is not sufficient to consider corrosion losses based only on measured losses on coupons-the physical extent of the steel component or structure within the region about the waterline must be considered. This is particularly the case where the steel structure extends from the atmospheric zone continuously some depth into the immersion zone (Figure 1).

\section{CONCLUSIONS}

* Apart from greater corrosion below about the mean low water level, the mild steel strip extending continuously from the atmospheric exposure zone through the splash and tidal zones into the immersion zone produced a corrosion loss profile generally similar to the classical profiles reported by Humble, LaQue, and Larrabee. This profile has been attributed to the effect of differential aeration.

* The shorter strips, irrespective of length $(1,0.5$, or $0.2 \mathrm{~m}$ ), all showed corrosion loss profiles similar to those of individual coupons ( $0.1 \mathrm{~m}$ long), and these were similar but more defined than the classical pro- 
files reported for $0.3-\mathrm{m}$ square plates. This indicates that differential aeration was not, in general, a major factor for the shorter strips.

* However, where the shorter strips were exposed such that one end was in a more aggressive exposure zone than the rest of the strip, there was evidence of very high localized corrosion, most likely due to the effect of differential aeration.

* The greater-than-classical corrosion losses below about the mean low water level for the coupons and all the strips could be the result of microbiological influenced corrosion, but this possibility remains to be investigated in more detail.

* Scratch and scribe marks existing prior to exposure were found to cause high localized corrosion.

\section{ACKNOWLEDGMENTS}

The financial support of the Australian Research Council is acknowledged. The authors also acknowledge the cooperation of the Royal Australian Navy at Jervis Bay for providing a secure space and facilities for coupon and strip exposure testing over extended periods of time.

\section{REFERENCES}

1. A.A. Humble, Corrosion 5, 9 (1949): p. 292-302.

2. F. LaQue, "Corrosion Testing," Edgar Marburg Lecture, Proc. ASTM, vol. 51 (West Conshohocken, PA: ASTM International, 1951), p. 495-582.

3. C.A. Larrabee, Corrosion 14, 11 (1958): p. 21-24.
4. U.R. Evans, J. Soc. Chem. Ind. (London) 44 (1925): p. 163.

5. U.R. Evans, The Corrosion and Oxidation of Metals: Scientific Principles and Practical Applications (London, U.K.: Edward Arnold [Publishers], Ltd., 1960).

6. J.M.R. Genin, A.A. Olowe, B. Resiak, N.D. Benbouzid-Rollet, S. L'Haridon, M. Confente, D. Prieur, "Microbially Induced Corrosion of Steel Sheet Piles in a Harbour and the Presence of Green Rust Two Compound," in Progress in the Understanding and Prevention of Corrosion, eds. J.M. Costa, A.D. Mercer (London, U.K.: The Institute of Metals, 1993), p. 1,177-1,184.

7. R.J. Gubner, "Accelerated Low Water Corrosion of Carbon Steel in Tidal Waters" (Ph.D. thesis, University of Portsmouth, UK, 1998)

8. R.E. Melchers, R. Jeffrey, Electrochim. Acta 54 (2008): p. 80-85.

9. A. Takamara, K. Arakawa, K. Fujiwara, H. Hirose, Trans. ISIJ 11 (1971): p. 299-306.

10. J.M. Odom, "Industrial and Environmental Activities of SulfateReducing Bacteria," in The Sulfate-Reducing Bacteria: Contemporary Perspectives, eds. J.M. Odom, Rivers Singleton, Jr. (New York, NY: Springer Verlag, 1993), p. 189-210.

11. Y. Li, B. Hou, H. Li, J. Zhang, Mater. Corros. 55, 4 (2004): p. 305 309.

12. C.R. Southwell, J.D. Bultman, C.W. Hummer, "Estimating Service Life of Steel in Seawater," in Seawater Corrosion Handbook, ed. M. Schumacher (Park Ridge, NJ: Noyes Data Corp. 1979), p. 374-387.

13. J. Jeffrey, R.E. Melchers, Corrosion 63, 9 (2007): p. 872-879.

14. B.W. Forgeson, C.R. Southwell, A.L. Alexander, Corrosion 163 (1960): p. 8,796.

15. R.E. Melchers, R. Jeffrey, Corrosion 60, 7 (2004): p. 697-703.

16. ASTM Standard G3-89, "Standard Practice for Conventions Applicable to Electrochemical Measurements in Corrosion Testing" (West Conshohocken, PA: ASTM International, 2004), doi: 10.1520/G0003-89R04.

17. R. Jeffrey, R.E. Melchers, "Corrosion of Vertical Mild Steel Strips in Seawater," Corros. Sci., doi: 10.1016/j.corsci.2009.06.020.

18. L.L. Shrier, "Localized Corrosion," in Corrosion, vol. 1, eds. L.L. Shrier, R.A. Jarman, G.T. Burstein, 3rd ed. (Oxford, U.K.: Butterworth-Heinemann, 1994).

19. R.E. Melchers, Corrosion 63, 5 (2007): p. 405-415.

20. R. Jeffrey, R.E. Melchers, Corros. Sci. 49 (2007): p. 2,270-2,288.

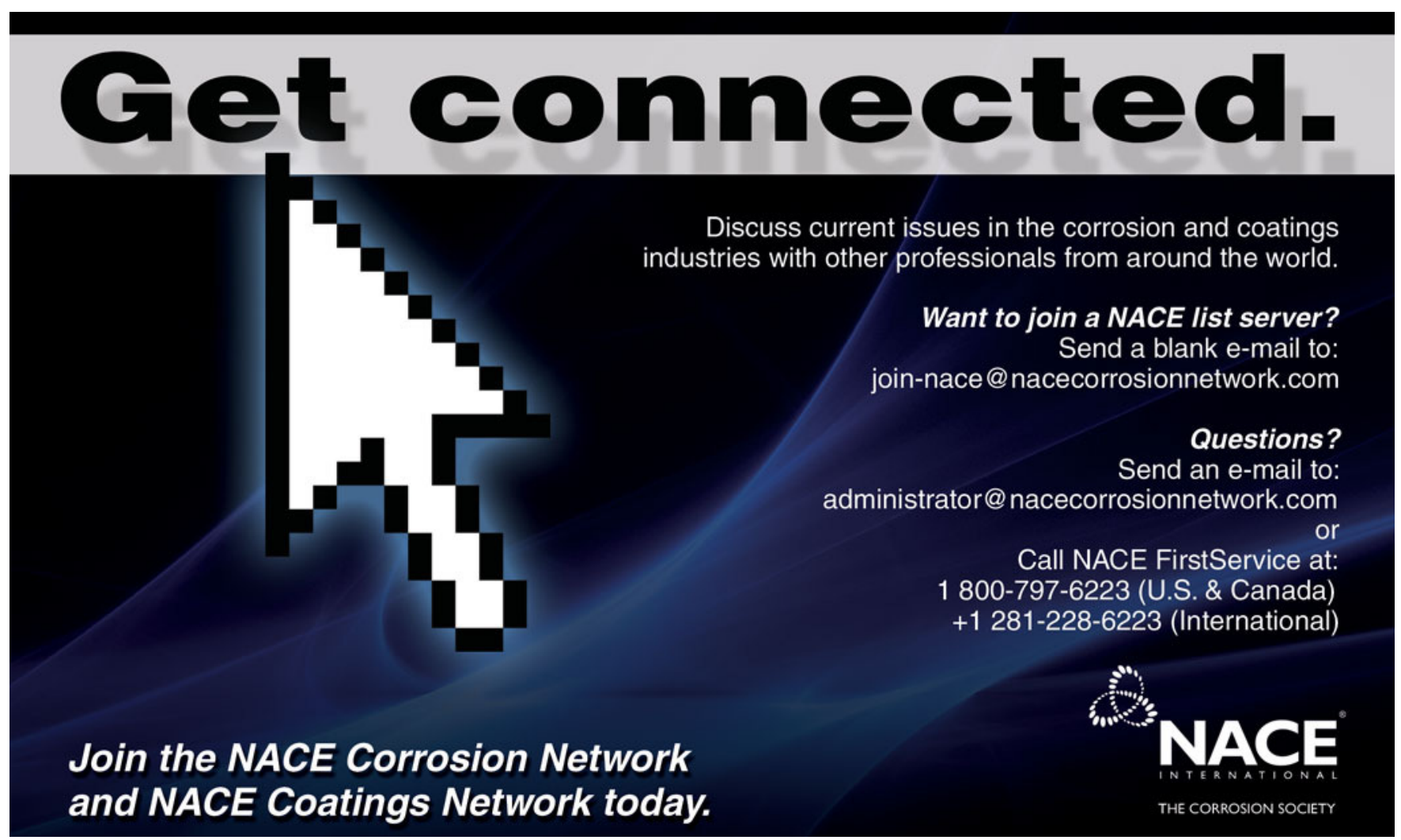

